\title{
Discriminative Power and Retrieval Effectiveness of Phrasal Indexing Terms
}

\author{
Sumio Fujita \\ Justsystem corporation \\ Brainspark, Tokushima, Japan \\ Email: Sumic_Fujita@justsystem.co.jp
}

\begin{abstract}
In spite of long controversy, effectiveness of phrasal indexing is not yet clear.

Recently, correlation between query length and effect of phrasal indexing is reported.

In this paper, terms extracted from the topic set

of the NACSIS test collection 1 are analyzed

utilizing statistic tools in order to show

distribution characteristics of single

word/phrasal terms with regard to relevant/non-

relevant documents. Phrasal terms are found to

be very good discriminators in general but not

all of them are effective as supplemental phrasal terms. A distinction of informative / neutral /

destructive phrasal terms is introduced. Retrieval effectiveness is examined utilizing query weight ratio of these three categories of phrasal terms.
\end{abstract}

\section{Introduction}

Longer queries are not necessarily better than shorter queries in view of retrieval effectiveness, since longer queries may contain so-called noisy terms that hurt the performance.

Given relevance judgements, we can say which terms are noisy and which are not with regard to a certain topic description and a test collection.

We can confirm that a term is good to discriminate subject concepts if relevant documents contain such terms and non-relevant documents do not contain them and that a term is noisy if the situation is the opposite.

The problem here is that not only noisy terms but also good terms can harm the performance in some cases where term weighting is not adequate or terms are redundant.
One example of such cases is complex terms like supplemental phrases or overlap bigrams which violate term independence assumption. Phrasal terms are utilized either as replacement of single words or as supplemental units for single words, but according to our experience, phrasal terms as replacement of single words do not perform well. Supplemental phrasal terms works better in spite of the violation of term independence assumption.

Recent studies uncovered the correlation between phrase effectiveness and query length(Fujita, 2000).

In this paper, we will see the problem of effectiveness of phrasal terms from two different viewpoints utilizing a large test collection for Japanese text retrieval and statistical tools.

NACSIS test collection 1(NTCIR, 1999), which consists of a collection of abstracts of scientific papers ( 330,000 records, $590 \mathrm{MB}$ in text ), two sets of topic description ( 30 topics for training and 53 topics for evaluation ) and relevance judgement, provides us of a good opportunity for this purpose.

Topic description of NACSIS test collection 1 contains four different fields, just like early versions of TREC topics, as follows:

$<$ title $>$ fields consist of one ( typically simple ) noun phrase.

<description> fields consist of one ( typically simple ) sentence.

<narrative> fields consist of 3 to 12 sentences and contain detailed explanation of the topic, term definition, background knowledge, purpose of the search, preference in text types, criteria of relevance judgement and so on.

<concepts> fields consist of lists of keywords corresponding to principal concepts in the information need.

Combining these four fields, different length of query sets for the same topics are prepared. 


\begin{tabular}{|c|c|c|c|c|c|}
\hline Topic field used & $\begin{array}{l}\text { Avg.Precl } \\
\text { (Single } \\
\text { words } \\
\text { only) } \\
\end{array}$ & $\begin{array}{l}\text { Avg.Prec2 } \\
\text { (Single } \\
\text { words \& } \\
\text { Phrases) } \\
\end{array}$ & $\begin{array}{l}\text { Avg.Prec2 } \\
\text { Avg.Prec1 }\end{array}$ & $\begin{array}{l}\text { Avg. } \\
\text { number } \\
\text { of total } \\
\text { terms }\end{array}$ & $\begin{array}{l}\text { Avg. } \\
\text { number } \\
\text { of phrasal } \\
\text { terms }\end{array}$ \\
\hline <description> & 0.3143 & 0.2846 & -0.0297 & 8.8 & 1.9 \\
\hline$<$ title $>$ & 0.2555 & 0.2265 & -0.029 & 4.1 & 1.0 \\
\hline$<$ title $>$, < description $>$ & 0.3334 & 0.3079 & -0.0255 & 9.2 & 2.1 \\
\hline$<$ title $>$, $<$ narrative $>$ & 0.3095 & 0.3001 & -0.0094 & 45.0 & 10.3 \\
\hline <narrative $>$ & 0.2985 & 0.2895 & -0.009 & 44.7 & 10.2 \\
\hline$<$ description $>$, <narrative $>$ & 0.3161 & 0.3163 & 0.0002 & 46.4 & 10.8 \\
\hline$<$ title $\rangle$, $<$ description $>$, <narrative $>$ & 0.321 & 0.3233 & 0.0023 & 46.5 & 10.9 \\
\hline$<$ description $>$, <concepts $>$ & 0.3672 & 0.3786 & 0.0114 & 25.4 & 5.2 \\
\hline$<$ narrative $>$, <concepts $>$ & 0.364 & 0.3761 & 0.0121 & 57.0 & 12.5 \\
\hline$<$ title $>,<$ description $>$, <concepts $>$ & 0.379 & 0.3926 & 0.0136 & 25.5 & 5.3 \\
\hline$<$ title $>$, $<$ narrative $>$, <concepts $>$ & 0.3702 & 0.3844 & 0.0142 & 57.3 & 12.7 \\
\hline$<$ description $>$, <narrative $>$, <concepts $>$ & 0.3681 & 0.3839 & 0.0158 & 58.4 & 13.1 \\
\hline$<$ title $>$, $<$ description $>$, $<$ narrative $>$, <concepts $>$ & 0.371 & 0.3886 & 0.0176 & 58.4 & 13.1 \\
\hline <concepts $>$ & 0.3316 & 0.3504 & 0.0188 & 20.9 & 4.1 \\
\hline$\langle$ title $\rangle$, <concepts $\rangle$ & 0.352 & 0.3711 & 0.0191 & 21.8 & 4.5 \\
\hline
\end{tabular}

Table 1: Performance comparison using 15 different versions of queries combining 4 fields

\section{Phrasal Indexing}

For the baseline run experiments, we utilized the engine of Conceptbase Search 1.2, a commercial based search engine adopting vector space model approach.

\subsection{Linguistic Phrases as Indexing Units for Japanese Text Retrieval}

For automatic indexing of Japanese written text, once word boundary is detected by morphological analysis processing, word based approach normally adopted in English IR can be applied. Although computationally more expensive than in English, the accuracy of Japanese morphological analysis is quite high and sufficient for IR purpose.

Our approach consists of utilizing noun phrases extracted by linguistic processing as supplementary indexing terms in addition to single word terms contained in phrases. Phrases and constituent single word terms are treated in the same way, both as independent terms, where the frequency of each term is counted independently based on its occurrences.

Linguistic phrases are normally contiguous kanji or katakana word sequences and internal phrase structures are ignored.

\subsection{Query Length and Effectiveness of Phrasal Indexing}

Among evaluation experiments of the NTCIR1 workshop, correlation between query length and the effect of phrasal indexing is reported in (Fujita, 1999).

NTCIR topic description consists of four fields namely <title>, <description>, <narrative> and $<$ concepts> as shown in the previous chapter. The combination of these four fields makes 15 different versions of queries for each topic. These 15 different versions of queries for 53 topics are examined with phrasal terms and with only single word terms.

Table 1 shows the performance with 15 versions of queries, where we compared two types of indexing language in question i.e. single words vs. single words + supplemental phrases. Performance is indicated as non-interpolated average precision macro averaged for 53 topics. Since this experiment is designed to clarify the effect of different length of queries, the following settings are chosen: 
1) no pseudo feedback procedure is processed,

2) no down-weighting coefficient is applied for phrasal terms,

3) no field specific importance coefficient is applied.

Consequently, absolute performance is much worse than our best performing runs.

Out of 15 versions of query sets, 10 times phrasal indexing performs better than single word only indexing, and 5 times vice versa. This is exactly the situation described in literature that the effect of phrasal indexing is inconsistent and uncertain.

We found out that there is clear correlation between the difference of average precision and number of terms contained in the query. Pearson's correlation coefficient between Avg. prec2 - Avg.prec1 and average number of terms accounts for 0.57 , while 0.52 between Avg. prec2 - Avg.precl and average number of phrases. Eliminating 8 query versions containing <concepts> field, correlation coefficients become 0.96 and 0.95 respectively.

<concepts> fields containing keywords that are essentially noun phrases, tend to favor phrasal indexing otherwise when using only one of the fields, single word runs perform better.

The situation is different when more than two fields are combined. Combining <title>, <description> and <narrative> fields, the supplemental phrasal run performs better than the single word run.

We can see that the length of query, which is number of features in the scoring function, is important factor as well as quality of phrasal terms extracted from topic description, in order to evaluate phrasal indexing.

Two aspects of characteristics of phrasal terms should be considered:

1) Are the phrasal terms good discriminator of subject domain?

2) Do the supplemental phrasal terms cause some undesirable influence to original word based queries?

In the chapter 2 , phrasal terms extracted from the topic set of the NACSIS test collection 1 are examined from the viewpoints of their discriminative power. In the chapter 3 , we will see another aspect of retrieval effectiveness.

\begin{tabular}{|l|l|}
\hline Df & Term \\
\hline 98561 & 研究(research) \\
\hline 83016 & 結果(result) \\
\hline 69911 & 3 \\
\hline 64675 & 報告(report) \\
\hline 63956 & 特性(characteristics) \\
\hline 61063 & 構造(structure) \\
\hline 58664 & 方法(method) \\
\hline 58410 & システム(system) \\
\hline 56807 & 解析(analysis) \\
\hline 50246 & 影響(influence) \\
\hline 47620 & 評価(evaluation) \\
\hline 42130 & 利用(use) \\
\hline 41584 & モデル(model) \\
\hline 41238 & 処理(process) \\
\hline 37567 & 時間(time) \\
\hline
\end{tabular}

Table 2: High document frequency single word terms

\begin{tabular}{|l|l|}
\hline Df & Term \\
\hline 12817 & 有効 性(effectiveness) \\
\hline 6969 & 3 次元(3-dimension) \\
\hline 5716 & モデル 化(modeling) \\
\hline 5183 & 効率 的(efficient) \\
\hline 4659 & 光 ファイバー(optic fiber) \\
\hline 2648 & 利用 者(user) \\
\hline 1795 & 高齢 者(old people) \\
\hline 1661 & 有効 利用(effective use) \\
\hline 1347 & $\begin{array}{l}\text { 遺伝 的 アルゴリズム } \\
\text { (genetic algorithm) }\end{array}$ \\
\hline 1345 & 階層 的(hierarchy) \\
\hline 1038 & a $\mathrm{t}$ m 網(ATM network) \\
\hline 860 & グループ ウエア(groupware) \\
\hline 799 & 人エ 知能(artificial intelligence) \\
\hline 777 & データ 転送(data transmission) \\
\hline 672 & $\begin{array}{l}\text { 分散 環境 } \\
\text { (distributional environment) }\end{array}$ \\
\hline
\end{tabular}

Table 3: High document frequency phrasal terms 

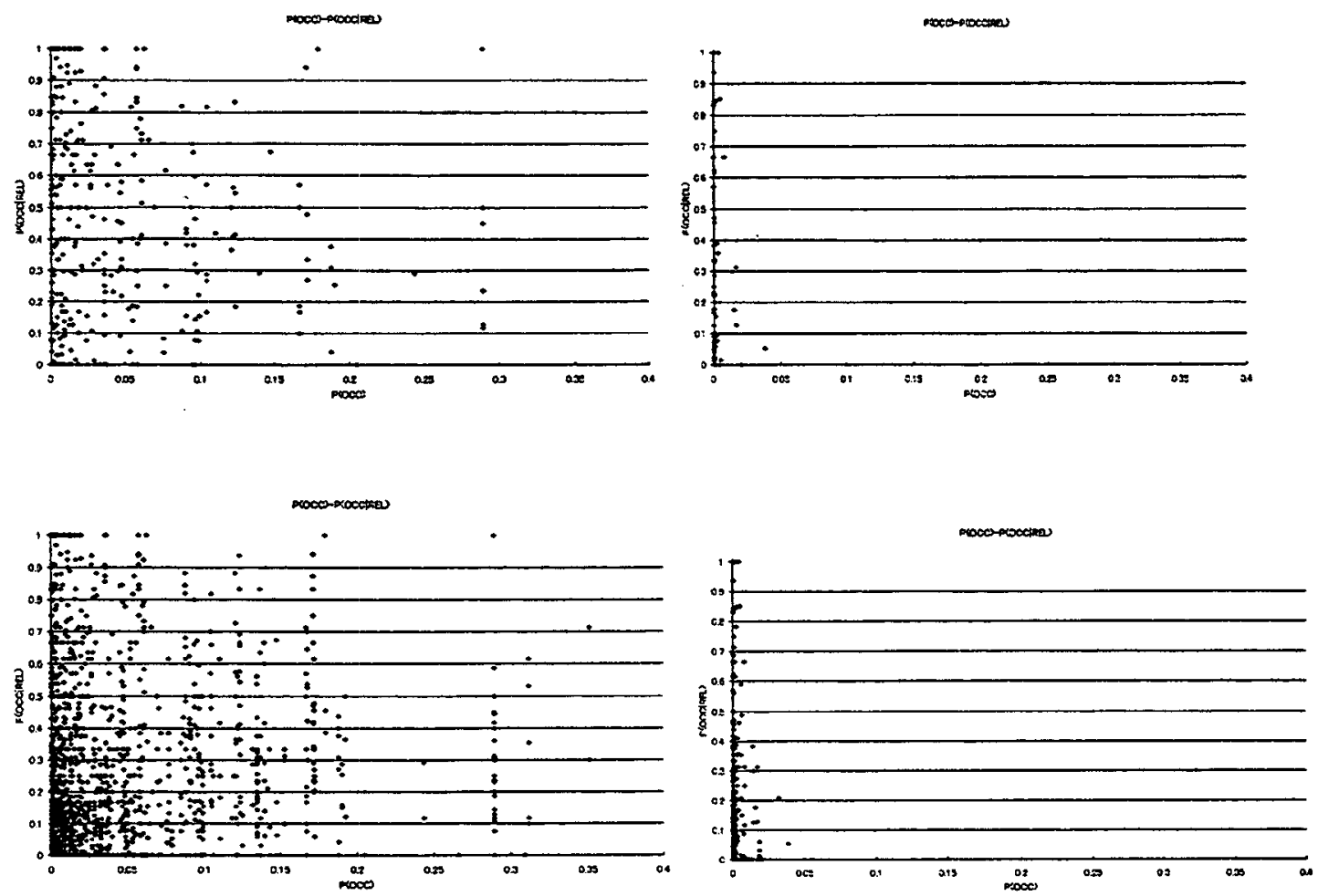

Figure 1: $p(o c c \mid r e l)$ as function of $p(o c c)$

Left above: short query single words, Right above: short query phrases

Left below: long query single words, Right below: long query phrases

\section{NTCIR Data Analysis}

Greiff presented an analysis of TREC data plotting each query terms in view of distributions in the whole document collection and in relevant document sets(Greiff, 1998) and Pickens et al. applied this analysis for statistical phrases(Pickens et al, 2000).

Adopting their plotting approach, we will try to clarify distribution characteristics of phrasal terms using mainly $p(o c c \mid r e l)$ and $p(o c c)$ which are computed as document frequencies of the term in relevant documents /the whole collection respectively divided by each number of documents.

\subsection{Occurrence in Relevant Documents and in Non-relevant Documents}

Table 2 and Table 3 shows high document frequency terms extracted from the short query set of test topics.
A short query refers to a query constructed using only <description> field of topic description and a long query, all fields of topic description.

First, plotting of $p$ (occ|non-rel) as function of $p(o c c)$ is not interesting since approximately the relation $p(o c c \mid n o n-r e l)=p(o c c)$ is observed. This is not surprising because number of relevant documents are generally very small and $\mathrm{p}$ (occ|non-rel) can be approximated by $\mathrm{p}(\mathrm{occ})$.

From Table 2 and Table 3, we can imagine that the distribution characteristics of phrasal terms are almost same as single words i.e. Zipfian distribution but document frequencies of phrasal terms are much smaller than single words.

It seems difficult to get clear intuition about term distribution characteristics from Figure 1, where $p(o c c \mid r e l)$ is plotted as function of $p(o c c)$. The same $p(o c c)$ value for some frequent terms found in plots indicates multiple occurrences of a term in different queries.

As Greiff suggests, a different visualization is desirable for this graph. 

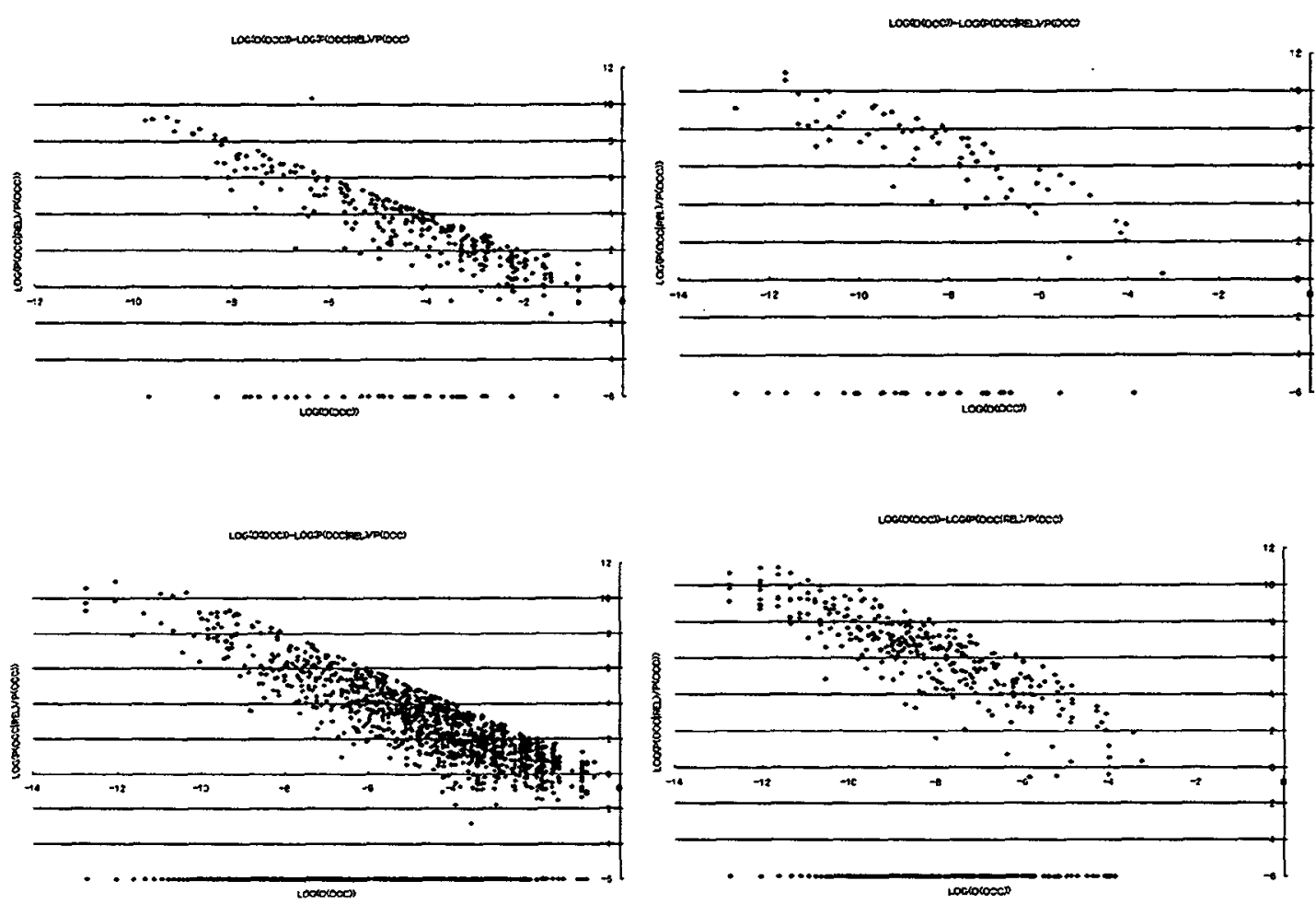

Figure 2: $\log (\mathrm{p}(\mathrm{occ} \mid \mathrm{rel}) / \mathrm{p}(\mathrm{occ}))$ as function of $\log (\mathrm{O}(\mathrm{occ}))$

Left above: short query single words, Right above: short query phrases

Left below: long query single words, Right below: long query phrases

First $\mathrm{p}(\mathrm{occ})$ is replaced by $\log (\mathrm{O}(\mathrm{occ}))=\log (\mathrm{p}(\mathrm{occ}) / 1-\mathrm{p}(\mathrm{occ}))$, since distribution of $p(o c c)$ is too skewed.

In Figure 1, if the dot representing a term located higher than the graph of $p(o c c)=p(o c c \mid r e l)$, the term can be a good discriminator and should contribute to retrieval performance given an adequate weighting scheme. On the other hands, the terms plotted lower than the graph of $p(o c c)=p(o c c \mid r e l)$ are by no means useful for retrieval performance irrespective of weighting scheme.

$\mathrm{P}($ occ|rel $)$ is replaced by $\log (\mathrm{p}(\mathrm{occ} \mid \mathrm{rel}) / \mathrm{p}(\mathrm{occ}))$ in order to illustrate this borderline. In the case of zero probability for $p(o c c \mid r e l),-6$ is assigned for $\log (\mathrm{p}(\mathrm{occ} \mid \mathrm{rel}) / \mathrm{p}(\mathrm{occ}))$.

This is equivalent to mutual information $\mathrm{MI}$ (occ;rel) in information theory as follows:

$\log \left(\frac{p(o c c \mid r e l)}{p(o c c)}\right)=\log \left(\frac{p(o c c, r e l)}{p(o c c) p(r e l)}\right)$

Finally, Figure 2 illustrates distribution characteristics of terms much better than Figure 1.

The dots plotted above the $y=0$ line represent useful terms with respect to the query and

\begin{tabular}{|l|l|l|l|}
\hline & Single words & Phrases & Single words + phrases \\
\hline Short query & $79.29 \%(291 / 367)$ & $66.34 \%(67 / 101)$ & $76.50 \%(358 / 468)$ \\
\hline Long query & $54.77 \%(1315 / 2401)$ & $45.32 \%(315 / 695)$ & $52.65 \%(1630 / 3096)$ \\
\hline
\end{tabular}

Table 4: Ratio of positive $\log (\mathrm{p}(\mathrm{occ} \mid \mathrm{rel}) / \mathrm{p}(\mathrm{occ}))$ for query terms 


\begin{tabular}{|l|l|l|l|}
\hline & Single words & Phrases & Single words + phrase \\
\hline Short query & 2.81 & 4.38 & 3.15 \\
\hline Long query & 1.65 & 2.92 & 1.93 \\
\hline
\end{tabular}

Table 5: Average of positive $\log (\mathrm{p}(\mathrm{occ} \mid \mathrm{rel}) / \mathrm{p}(\mathrm{occ}))$ value for query terms

relevance judgements.

As this shows, single words and phrases are very similar distribution characteristics but document frequencies for phrases are much lower. Average of $\log (O(O c c))$ is -5.22 for single words while 8.64 for phrases in long queries.

On the other hands, ratios of good terms, whose $\log (\mathrm{p}(\mathrm{occ} \mid \mathrm{rel}) / \mathrm{p}(\mathrm{occ}))$ is larger than 0 , are shown in Table 4.

From this observation, we can see limited usefulness of phrasal terms with regards to relevance. The ratio of positive $\log (\mathrm{p}(\mathrm{occ} \mid \mathrm{rel}) / \mathrm{p}(\mathrm{occ}))$ is lower than single words. This explains poor performance of precoordinated longer phrase based indexing that utilizes phrases as replacements of single words. Phrasal terms tend to have high value of $\log (\mathrm{p}(\mathrm{occ} \mid \mathrm{rel}) / \mathrm{p}(\mathrm{occ}))$, but this does not necessarily mean effectiveness of phrasal terms. As Figure 1 and Figure 2 illustrate, the terms with high $\log (\mathrm{p}(\mathrm{occ} / \mathrm{rel}) / \mathrm{p}(\mathrm{occ}))$ value tend to have low $\log (\mathrm{O}(\mathrm{occ}))$ that means extremely lower document frequency so that they are not so useful because of such lower frequency.

\subsection{Measures for Phrasal Term Effectiveness}

Table 4 and Table 5 seem to support supplemental phrasal indexing, because fairly high ratio of positive $\log (\mathrm{p}(\mathrm{occ} \mid \mathrm{rel}) / \mathrm{p}(\mathrm{occ}))$ terms, and higher average value of $\log (\mathrm{p}(\mathrm{occ} \mid \mathrm{rel}) / \mathrm{p}(\mathrm{occ}))$ are observed. But for short queries, supplementing phrasal terms did not show any positive effect as we have seen in Table 1.

The following accounts are enumerated.

1) Over-weighted phrasal terms may cause topic deviation from concepts represented by single words to concepts represented by phrasal terms.

2) Supplemental phrasal terms are not always informative because their constituent single words are already indexed.

If the phrasal term $A B$ has a high $M(A B$,rel) value in contrast with $\mathrm{MI}(\mathrm{A}, \mathrm{rel})$ and $\mathrm{MI}(\mathrm{B}, \mathrm{rel})$, this is the case where phrasal terms are effective.

Consider a supplemental phrasal term as informative if and only if its $\mathrm{MI}(\mathrm{occ}, \mathrm{rel})$ is positive value and is higher than the sum of $\mathrm{MI}$ (occ,rel) of constituent single words in view of the query and relevance judgements. A phrase "AB" is informative means that the occurrence of a phrase "AB" gives more information about relevance than occurrence of both single words " $A$ " and "B".

Table 6 shows the number and the ratio of informative phrasal terms. -1 is assigned for MI(occ,rel) when p(occ|rel) is 0 .

Giving different values $(-3$ and -6$)$ for MI(occ|rel) when $p$ (occ|rel) $=0$ did not change the results..

\begin{tabular}{|l|l|l|l|}
\hline & $\begin{array}{l}\text { \{\#phrasal terms } \mid \text { MI(AB,rel) }> \\
\text { SUM( MI(A,rel), MI(B,rel)) }\end{array}$ & $\begin{array}{l}\text { Positive MI(occ,rel) } \\
\text { phrasal terms }\end{array}$ & Total phrasal terms \\
\hline Short query & $31(30.69 \%)$ & $67(66.34 \%)$ & 101 \\
\hline Long query & $146(21.01 \%)$ & $315(45.32 \%)$ & 695 \\
\hline
\end{tabular}

Table 6: Number of informative phrasal terms 


\begin{tabular}{|l|l|}
\hline Category & Phrasal terms \\
\hline Informative & $\begin{array}{l}\text { 転送 レート 制御(transmission rate control),フロー 制御 (flow control), } \\
\text { レート 制御 (rate control) }\end{array}$ \\
\hline Neutral & $\begin{array}{l}\text { マルチ キャスト 通信(multicast communication),マルチ キャスト } \\
\text { (multicast), }\end{array}$ \\
\hline Destructive & $\begin{array}{l}\text { 研究 動向(research trend),部分 的(partial),関連 性(relatedness),送信者 } \\
\text { 側 (sender side),複数 データ(multiple data),マルチ キャスト 環境 } \\
\text { (multicast environment),マルチメディア データ(multimedia data),受信 } \\
\text { 者 (receiver) }\end{array}$ \\
\hline
\end{tabular}

Table 7 : Examples of phrasal terms in three categories from NACSIS topic 31

\subsection{Three Categories of Phrasal Terms}

The following three categories of phrasal terms in view of possible contribution to retrieval effectiveness are proposed from the previous discussion.

1) Informative phrasal terms : MI(occ,rel) > $\Sigma \mathrm{MI}$ (occ of constituent single words, rel).

2) Neutral phrasal terms :

$\Sigma \mathrm{MI}$ (occ of constituent single words, rel) $>$ MI (occ,rel) $>=0$.

3) Destructive phrasal terms : MI(occ,rel) $<0$.

For example, Table 7 shows phrasal terms extracted from all fields of topic 31 in NACSIS test collection 1,and classified accordingly.

\subsection{Weight Ratio of Phrasal Terms}

Retrieval status values are computed as a linear combination of each term weight, which is the product of the query weight and the document weight of the term. Using atn weighting in the SMART system for the same setting as the runs reported in Table 1, for each query term, the sums of weights of each query term are computed and for each query weight sum, ratio of informative phrasal terms and destructive phrasal terms are also computed. Macroaveraged ratios of informative phrasal terms and destructive phrasal terms are shown in Table 8. Still, short queries seem to contain better phrases in the ratio despite the fact that no consistent effectiveness for retrieval performance is observed.

\subsection{Correlation between phrasal term weight ratio and performance difference}

For each runs against the 53 test topic set both with short queries and long queries, correlation between query-by-query performance difference and query-by-query weight ratio of both informative and destructive phrasal term weight ratio are examined. Performance difference is measured by non-interpolated average precision and when the supplemental phrasal term run performs better a positive value is given as we have seen in Table 1.

Table 9 shows the Pearson's correlation coefficient between performance difference and each weight ratio as well as and difference between weight ratios.

\begin{tabular}{|l|l|l|l|l|}
\hline & $\begin{array}{l}\text { Average weight } \\
\text { ratio of informative } \\
\text { phrases }\end{array}$ & $\begin{array}{l}\text { Number of topics } \\
\text { Containing } \\
\text { informative phrases }\end{array}$ & $\begin{array}{l}\text { Average weight } \\
\text { ratio of destructive } \\
\text { phrases }\end{array}$ & $\begin{array}{l}\text { Number of topics } \\
\text { containing } \\
\text { destructive phrases }\end{array}$ \\
\hline Short query & $8.59 \%$ & 25 & $10.40 \%$ & 26 \\
\hline Long query & $6.47 \%$ & 47 & $16.14 \%$ & 53 \\
\hline
\end{tabular}

Table 8 : Weight ratio of phrasal terms ( macro-averaged for 53 topics ) 


\begin{tabular}{|l|l|l|l|}
\hline & $\begin{array}{l}\text { Informative phrasal } \\
\text { term weight ratio(A) }\end{array}$ & $\begin{array}{l}\text { Destructive phrasal term } \\
\text { weight ratio(B) }\end{array}$ & (A)-(B) \\
\hline Short query & 0.12 & -0.05 & 0.11 \\
\hline Long query & 0.02 & -0.05 & 0.04 \\
\hline
\end{tabular}

Table 9 : Pearson's correlation between performance difference and phrasal term weight ratio

A positive correlation coefficient for informative phrasal terms and a negative correlation coefficient for destructive phrasal terms are observed as is expected, although the coefficient values are very small.

Given a topic set, a document collection and relevance judgements, we are able to know which terms are good ( and possibly how good they are ) for retrieval performance but to explain slight performance difference between different indexing strategies seems to be much more difficult.

Short queries contain relatively better phrasal terms even though absolute number of such terms is smaller than longer queries. But utilizing such phrasal terms does not always lead to performance improvement in macro-averaged precision-recall basis evaluation.

\section{Topic Deviation}

What we mean by topic deviation is a phenomenon that is similar to query drift caused by relevance feedback, but is incurred by some over-weighted supplemental phrasal terms. Terms representing some concepts in the topic are over-weighted consequently the search results are inclined to these concepts.

We verified short queries where supplemental phrasal terms caused considerable degradation (difference in average precision is more than $20 \%$ ) and listed phrasal terms caused such degradation in Table 10.

As we can see, not only the neutral phrases in topics 50,62 and 77, but also adding only informative phrases caused degradation as in topic 76.

<description> field of topic 76 is translated as follows:
"(I want to know about) methods for interference detection between polyhedral representations."

This topic consists of two concepts namely "interference detection" and "polyhedral representation" and the supplemented phrasal tem “多面体 間”(between polyhedral) is part of the second concept.

Retrieval effectiveness depends on a subtle balance of weighting on each concept, especially in short queries, and redundant terms or overweighted terms cause the scoring function to loose such balances.

\section{Conclusions}

Effects of phrasal indexing in view of different length of queries are observed in the experiments using NACSIS test collection 1, the first large scale test collection for Japanese information retrieval.

Our observations and conclusions are as follows: 1) Distribution characteristics of phrasal terms as well as single word terms are examined plotting each term's MI(occ,rel) as function of $\log (\mathrm{O}(\mathrm{occ}))$.

2) Distribution characteristics of phrasal terms are similar to single word terms but their frequencies are much smaller than single words.

3) Generally phrasal terms are comparably good discriminators of relevant documents, if not superior, as single words are.

4) In supplemental phrasal indexing, good discriminator terms are not always effective for retrieval performance but only some phrasal terms are informative and possibly effective.

5) Informative, neutral and destructive phrasal terms are defined by means of $\mathrm{MI}$ (occ,rel).

6) Correlation between performance difference and weight ratio of informative/destructive terms is examined and a very week correlation is observed. 


\begin{tabular}{|c|c|c|c|c|c|c|}
\hline Topic & Term & $p($ occ $)$ & $p($ occlrel) & $p\left(\right.$ occl $\left.\right|^{2}$ rel $)$ & $\begin{array}{l}\log (p(o c c \mid \\
\mathrm{rel}) / \mathrm{p}(\mathrm{occ}))\end{array}$ & Category \\
\hline 34 & $\begin{array}{l}\text { 改良 方法 } \\
\text { (improvement method) }\end{array}$ & 0.000129 & 0 & 0.000129 & -6 & Destructive \\
\hline 50 & $\begin{array}{l}\text { 人工 知能 } \\
\text { (artificial intelligence) }\end{array}$ & 0.002346 & 0.388889 & 0.002305 & 5.11063 & Neutral \\
\hline 60 & $\begin{array}{l}\text { 教育 問題 } \\
\text { (educational issues) }\end{array}$ & 0.000006 & 0 & 0.000006 & -6 & Destructive \\
\hline 60 & $\begin{array}{l}\text { 占領 期 } \\
\text { (occupation period) }\end{array}$ & 0.000012 & 0.222222 & 0.000006 & 9.848081 & Informative \\
\hline 60 & $\begin{array}{l}\text { 教育 事情 } \\
\text { (educational situation) }\end{array}$ & 0.000009 & 0 & 0.000009 & -6 & Destructive \\
\hline 62 & $\begin{array}{l}\text { 生涯 学習 } \\
\text { (life-long learning) }\end{array}$ & 0.00044 & 0.285714 & 0.000435 & 6.475054 & Neutral \\
\hline 76 & $\begin{array}{l}\text { 多面体 間 } \\
\text { (between polyhedral) }\end{array}$ & 0.000023 & 0.076923 & 0.000021 & 8.094061 & Informative \\
\hline 77 & $\begin{array}{l}\text { 点字 翻訳 } \\
\text { (braille transcription) }\end{array}$ & 0.000029 & 0.166667 & 0.000026 & 8.644108 & Neutral \\
\hline 78 & $\begin{array}{l}\text { 哺乳 動物 } \\
\text { (mammals) }\end{array}$ & 0.000414 & 0 & 0.000414 & -6 & Destructive \\
\hline 78 & $\begin{array}{l}\text { 不死 化 } \\
\text { (immortalize) }\end{array}$ & 0.000065 & 0.666667 & 0.000053 & 9.241945 & Informative \\
\hline
\end{tabular}

Table 10: Phrasal terms in degraded topics by supplemental phrases

7) Explaining effectiveness of each query term is not sufficient for explaining effectiveness of phrasal indexing. Even good discriminator terms may hurt the retrieval effectiveness.

This research is by no means conclusive but a starting point of a longer project that hopefully leads to a new weighting scheme to replace current empirical down-weighting approach for supplemental phrasal terms.

\section{Acknowledgements}

The author thanks NACSIS R\&D department for providing us of NACSIS test collection 1 . We participated in the NTCIR workshop utilizing NACSIS test collection 1 (preliminary version) that is developed by NACSIS R\&D department, thanks to understanding of academic societies (http://www.rd.nacsis.ac.jp/ ntcadm/thankslen html) who provided the data.

\section{References}

[1] Fujita, S. (1999). Notes on Phrasal Indexing: JSCB Evaluation Experiments at NTCIR AD HOC, NTCIR Workshop 1, Tokyo, 101108.

[2] Fujita, S. (2000). Evaluation of Japanese Phrasal Indexing with a Large Test Collection, RIAO2000 Conference proceedings, Paris, 1089-1098.

[3] Greiff, W.R. (1998). A Theory of Term Weighting Based on Exploratory Data Analysis, SIGIR '98, Melbourne, 11-19.

[4] NTCIR. (1999). http://www.rd.nacsis.ac.jp/ ntcadm/indexen.html.

[5] Pickens, J. Croft, W.B. (2000) An Exploratory Analysis of Phrases in Text Retrieval, RIAO2000 Conference proceedings, Paris, 1179-1195. 